\title{
The Effect of Pneumonia Induced in Mice with Mycoplasma pulmonis on Resistance to Subsequent Bacterial Infection and the Effect of a Respiratory Infection with Sendai Virus on the Resistance of Mice to Mycoplasma pulmonis
}

\author{
By C. J. HOWARD, E. J. STOTT AND GERALDINE TAYLOR \\ Agricultural Research Council, Institute for Research on Animal Diseases, \\ Compton, Newbury, Berkshire, RG16 0NN
}

(Received 12 June 1978)

\begin{abstract}
The effect of pneumonia induced by Mycoplasma pulmonis in mice on the resistance of the lung to additional bacterial infection was examined. The effect of pneumonia induced by Sendai virus on the resistance of mice to $M$. pulmonis was also investigated and compared with the effect of Sendai virus on resistance to Staphylococcus aureus. Sendai virus infection decreased subsequent resistance to $M$. pulmonis in proportion to the virus dose. Decreased resistarice to subsequent $S$. aureus and $M$. pulmonis infection was greatest at about the same time after inoculation of virus and was related to virus-induced lesions. Besides affecting the resistance of mice to subsequent mycoplasma infection, Sendai virus could enhance an existing mycoplasma infection. Pneumonia induced by $M$. pulmonis did not decrease resistance to subsequent bacterial infection. The mechanism whereby Sendai virus decreases host resistance is therefore similar for bacteria and mycoplasmas, but pneumonia induced by mycoplasmas does not have the same effect.
\end{abstract}

\section{INTRODUCTION}

Some respiratory diseases appear to involve more than a single causative agent. Frequently several species of micro-organism are isolated from pneumonic lungs. Furthermore, animals inoculated with a pure culture of an organism isolated from pneumonic tissue may not develop the same type of disease as that seen in the animal from which the agent was originally isolated. One experimental approach used in an attempt to understand this problem has been the inoculation of mixtures of micro-organisms into the respiratory tract of a variety of animal species. Thus, viable Pasteurella pneumotropica or Staphylococcus aureus were found to persist longer in mice previously infected with Sendai virus than in mice not so infected. The degree of decreased resistance to bacterial infection was related to the extent of virus-induced histopathological damage, but it was rather transient and was probably due to an effect of the virus on the ability of the defence mechanisms of the lung to kill the bacteria (Jakab \& Green, 1972; Jakab \& Dick, 1973; Jakab, 1975).

Mycoplasmas and bacteria are frequently present in pneumonic tissue, e.g. Mycoplasma gallisepticum and Escherichia coli in chickens (Fabricant, 1969), M. pulmonis and P. pneumotropica in mice (Brennan et al., 1969), and a variety of mycoplasmas and bacteria in calves (Gourlay et al., 1970). It was therefore of interest to examine whether pneumonia induced by a mycoplasma has the same effect on the survival of bacteria in the lung as respiratory disease induced by a virus. Accordingly experiments were undertaken to determine whether mice suffering from pneumonia due to $M$. pulmonis, a natural respiratory pathogen 
of mice, had an impaired ability to kill bacteria. Experiments were also performed to determine whether an infection with Sendai virus decreased the resistance of mice to a respiratory infection with $M$.pulmonis and whether any such decrease was of the same order or different from that observed with bacteria.

\section{METHODS}

Organisms. Mycoplasma pulmonis strain JB has been described previously (Taylor et al., 1977). The strain of Sendai virus was obtained from Dr P. Eaton, Charing Cross Hospital, London (Eaton, 1974). Staphylococcus aureus FDA 209P (ATCC 7538 P, NCTC 7447) (Shaw et al., 1951) was the strain previously used by Jakab \& Green (1972). The strain of Pasteurella pneumotropica was isolated at Compton from the pneumonic lung of a rat bred in a conventional colony.

Preparation of inocula. The medium used to grow M. pulmonis was that of Taylor et al. (1977). Small portions of broth culture of $M$. pulmonis were stored at $-70^{\circ} \mathrm{C}$ to provide a standard inoculum. Sendai virus was grown in secondary calf kidney cells, harvested and stored in $0.1 \mathrm{ml}$ portions at $-70^{\circ} \mathrm{C}$ to provide a standard inoculum. The bacteria were grown aerobically at $37^{\circ} \mathrm{C}$ on $5 \%(\mathrm{v} / \mathrm{v})$ ox-blood agar and suspensions were made in $0 \cdot 15 \mathrm{M}$-phosphate buffered saline $\mathrm{pH} 7 \cdot 2$ (PBS) from $24 \mathrm{~h}$ cultures.

Mice. Male CBA mice and random bred 'Compton white' mice, weighing 18 to $22 \mathrm{~g}$, were supplied by the Specific-Pathogen-Free unit at this Institute. Balb/c mice were obtained from Olac (Shaws Farm, Bicester). All mice were of the Medical Research Council Laboratory Animals Centre category 4 standard. Mice were anaesthetized by inoculating them intraperitoneally with $0.2 \mathrm{ml}$ of a solution of sodium pentobarbitone (Sagatal, May \& Baker, diluted $10^{-1}$ in PBS).

Inoculation and sampling of mice. To determine the effect of an infection with Sendai virus or M. pulmonis on the resistance of mice to subsequent infection with a second micro-organism, the general procedure was as follows. Anaesthetized mice were inoculated intranasally (i.n.) with $25 \mu \mathrm{l}$ of a suspension of either Sendai virus or M. pulmonis in PBS (Taylor et al., 1977). Previously infected mice and control mice of the same age were subsequently exposed to a second agent, administered either as an aerosol (M. pulmonis, S. aureus, $P$. pneumotropica) or intranasally as a suspension (Sendai virus).

The various schedules used were: (a) primary i.n. inoculation with $10^{6}$ colony-forming units (c.f.u.) $M$. pulmonis with a secondary 30 min exposure to $S$. aureus at intervals up to 6 weeks; (b) primary i.n. inoculation with $10^{4}$ plaque-forming units (p.f.u.) Sendai virus with a secondary $60 \mathrm{~min}$ exposure to $M$. pulmonis $6 \mathrm{~d}$ later; (c) primary i.n. inoculation with either $10^{2 \cdot 2}, 10^{3 \cdot 2}, 10^{4 \cdot 2}, 10^{5 \cdot 2}$ or $10^{6 \cdot 2}$ p.f.u. Sendai virus with a secondary 60 min exposure to $M$. pulmonis $6 \mathrm{~d}$ later; $(d)$ primary i.n. inoculation with $10^{3}$ p.f.u. Sendai virus with a secondary exposure to $S$. aureus for $30 \mathrm{~min}$ or $M$. pulmonis for $60 \mathrm{~min} 3,6,8,10$ or $13 \mathrm{~d}$ later; and $(e)$ primary i.n. inoculation with $10^{4 \cdot 7}$ c.f.u. $M$. pulmonis with a secondary i.n. inoculation with $10^{3 \cdot 2}$ p.f.u. Sendai virus $8 \mathrm{~d}$ later. At the time of exposure to or i.n. inoculation with the second agent, an equal number of uninfected mice were subjected to the same treatment, to act as controls. Unless otherwise stated, CBA mice were used throughout.

The aerosol was generated by means of a Collison jet atomizer (Microbiological Research Establishment, Salisbury) connected to a compressed air supply ( $5 \mathrm{lbf} \mathrm{in}^{-2}=34 \mathrm{kPa}$ ) from a cylinder. The spray so generated was fed into a chamber containing the mice. The number of bacteria or mycoplasmas in the atomizer was about $10^{9} \mathrm{ml}^{-1}$ in PBS containing $40 \%$ (v/v) Hartley's digest broth.

Immediately after exposure to the second infective agent, four mice from both the test and control groups were killed by $0.2 \mathrm{ml}$ intraperitoneal Sagatal. Lung washings, obtained by irrigation with $1 \mathrm{ml}$ PBS, were titrated to determine the number of c.f.u. $M$. pulmonis and bacteria or p.f.u. Sendai virus $\mathrm{ml}^{-1}$ in lung wash fluid. In addition the number of leucocytes $\mathrm{ml}^{-1}$ in lung wash fluid was determined to provide an indication of the degree of inflammation in the lung. The lungs were then fixed in formalin for sectioning and histopathological examination to determine the state of the lungs. In the case of schedules $(a),(c)$ and $(d)$ a further four mice from both the test and control groups were killed $24 \mathrm{~h}$ after exposure to the second infective agent and lung washings were titrated to determine the number of the second infective agent present. In those experiments, schedules $(b)$ and $(e)$, in which mice were kept for longer than $24 \mathrm{~h}$ after exposure to the second infective agent, further groups of four mice from both the test and control groups were killed at specified intervals and lung washings were titrated to determine the number of first and second infective agents and leucocytes present. At the same time the lungs were fixed in formalin for sectioning and histopathological examination to determine the state of the lungs.

Histopathological assessment. The method of assessing pneumonic lesions was similar to that described previously (Taylor et al., 1977) except that the lesion scores for cuffing and parenchymal infiltration were combined; the maximum possible score was 6 .

Statistical analysis. The results of the experiments were analysed using a standard analysis of variance (one way classification). 
Table 1. Effect of intranasal inoculation of mice with $10^{6}$ c.f.u. M. pulmonis on their subsequent resistance to exposure to an aerosol of $S$. aureus

Condition of lungs at time of exposure to $S$. aureus

\begin{tabular}{|c|c|c|c|c|c|c|}
\hline \multirow{2}{*}{$\begin{array}{l}\text { Time after } \\
\text { inoculation } \\
\text { with } \\
\text { M. pulmonis } \\
\text { (d) }\end{array}$} & \multirow{2}{*}{$\begin{array}{c}\text { Mycoplasmas } \\
\mathrm{ml}^{-1} \text { in } \\
\text { lung wash* } \\
\left(10^{\mathrm{n}}\right)\end{array}$} & \multirow{2}{*}{$\begin{array}{c}\text { Leucocytes } \\
\mathrm{ml}^{-1} \text { in } \\
\text { lung wash* } \\
\left(10^{n}\right)\end{array}$} & \multirow[b]{2}{*}{$\begin{array}{l}\text { Lesion } \\
\text { score* }\end{array}$} & \multicolumn{2}{|c|}{$\begin{array}{l}\text { S. aureus } \mathrm{ml}^{-1} \\
\text { in lung wash* }\left(10^{\mathrm{n}}\right)\end{array}$} & \multirow{2}{*}{$\begin{array}{c}\text { Decrease } \\
\text { in } S \text {. aureus } \\
\text { in } 24 \mathrm{~h}\left(10^{\mathrm{n}}\right)\end{array}$} \\
\hline & & & & Initially & After $24 \mathrm{~h}$ & \\
\hline 0 & $<1$ & $4 \cdot 3$ & 0.1 & $5 \cdot 1$ & $3 \cdot 0$ & $2 \cdot 1$ \\
\hline 7 & $6 \cdot 8$ & $6 \cdot 3$ & $1 \cdot 6$ & $4 \cdot 0$ & 1.9 & $2 \cdot 1$ \\
\hline 14 & $6 \cdot 8$ & $6 \cdot 8$ & $1 \cdot 9$ & $4 \cdot 2$ & $1 \cdot 7$ & $2 \cdot 5$ \\
\hline 21 & $6 \cdot 8$ & $6 \cdot 5$ & $1 \cdot 5$ & $4 \cdot 5$ & $2 \cdot 6$ & 1.9 \\
\hline 28 & $6 \cdot 4$ & $6 \cdot 3$ & 0.9 & $4 \cdot 8$ & $2 \cdot 6$ & $2 \cdot 2$ \\
\hline 42 & 6.6 & $5 \cdot 9$ & 0.9 & $4 \cdot 6$ & $2 \cdot 4$ & $2 \cdot 2$ \\
\hline Standard error $\dagger$ & $0 \cdot 197$ & $0 \cdot 165$ & $0 \cdot 459$ & $0 \cdot 130$ & $0 \cdot 231$ & \\
\hline
\end{tabular}

* Mean of groups of four mice.

$\dagger$ Average standard error for comparisons between means in columns, by standard analysis of variance.

\section{RESULTS}

Effect of $M$. pulmonis infection on subsequent resistance to infection with $S$. aureus at intervals up to 6 weeks

Immediately after exposure to the aerosol, the numbers of $S$. aureus present in lung washings taken from mice before infection with $M$. pulmonis and, throughout the experiment, from control uninfected mice were of the same order $\left(10^{5 \cdot 1}\right)$, whereas the numbers in washings from mice infected with $M$. pulmonis were significantly less $(P<0.001)$. However, the decrease in the number of $S$. aureus over the first $24 \mathrm{~h}$ after exposure to the aerosol of bacteria, throughout the period of observation, was almost identical in all groups (Table 1). The experiment was repeated with identical results. In a third experiment, using Balb/c mice instead of CBA mice, the results obtained were again similar. In a final experiment the effect of infection with $M$. pulmonis on the susceptibility of 'Compton white' mice to $P$. pneumotropica was determined. Again no decreased resistance to bacterial infection was observed.

\section{Effect of Sendai virus infection on subsequent resistance to infection with M. pulmonis 6 d later}

At the time of exposure to the aerosol of $M$. pulmonis, the number of p.f.u. Sendai virus present in lung washings was $10^{5 \cdot 1 \pm 0 \cdot 38}$, the lesion score was $10^{0 \cdot 8_{ \pm} \cdot \cdot 18}$ and the lung wash cell count was $10^{6 \cdot 4 \pm 0 \cdot 11} \mathrm{ml}^{-1}$. Throughout the $6 \mathrm{~d}$ after exposure to $M$. pulmonis the numbers of mycoplasmas isolated from the lungs of mice infected with Sendai virus were significantly greater than the numbers isolated from the lungs of control mice, i.e. not previously infected with virus (Fig. 1). Mycoplasmas were not isolated from any of the mice inoculated with Sendai virus alone.

Mice examined $9 \mathrm{~d}$ after inoculation with Sendai virus alone had a lesion score of $10^{1 \cdot 5 \pm 0.35}$ compared with a lesion score of $10^{1 \cdot 9 \pm 0.59}$ for mice that had also been exposed to $M$. pulmonis and a lesion score of $10^{0 \cdot 1 \pm 0 \cdot 03}$ in mice that had been exposed to M.pulmonis alone. The number of cells in lung washings from these mice were $10^{6 \cdot 0 \pm 0 \cdot 22}, 10^{6 \cdot 4 \pm 0 \cdot 08}$ and $10^{4 \cdot 5 \pm 0 \cdot 13}$, respectively. Twelve days after inoculation of virus alone the lesion score was $10^{1 \cdot 5 \pm 0 \cdot 49}$ compared with lesion scores of $10^{1 \cdot 6 \pm 0 \cdot 35}$ in mice subsequently exposed to $M$. pulmonis and of $10^{0: 1+0 \cdot 02}$ in mice inoculated with $M$. pulmonis alone. The lung wash cell counts from these groups of mice were $10^{5 \cdot 5 \pm 0 \cdot 34}, 10^{7 \cdot 1 \pm 0 \cdot 18}$ and $10^{4 \cdot 1 \pm 0 \cdot 25}$, respectively. 


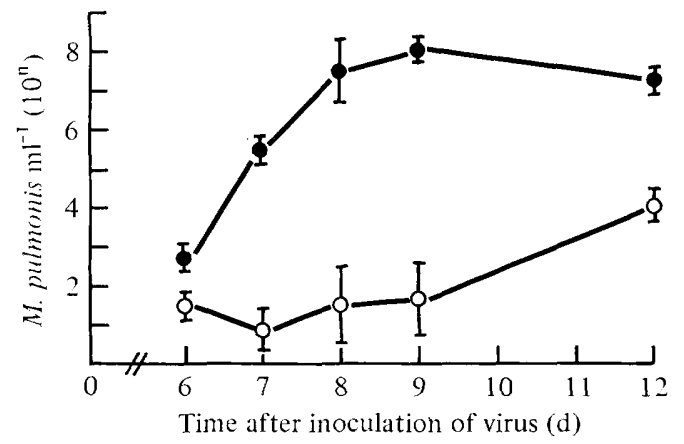

Fig. 1. Effect of Sendai virus infection on subsequent resistance to infection with $M$. pulmonis. Mice were exposed to an aerosol of $M$. pulmonis $6 \mathrm{~d}$ after i.n. inoculation of virus. Each point represents the mean number of c.f.u. M. pulmonis $\mathrm{ml}^{-1}$ in lung washings, together with the standard deviation, in groups of four mice infected $(\bullet)$ or not infected $(O)$ with virus.

Table 2. Effect of intranasal inoculation of mice with various doses of Sendai virus on their subsequent resistance to exposure to an aerosol of M. pulmonis $6 d$ later

Condition of lungs at time of exposure to $M$. pulmonis

Dose of Sendai virus (10 ${ }^{\text {n }}$ p.f.u.)

0

$2 \cdot 2$

$3 \cdot 2$

$4 \cdot 2$

$5 \cdot 2$

$6 \cdot 2$

Standard error $\dagger$

$\overbrace{\text { Sendai virus }}^{\text {Leucocytes }}$
$\mathrm{ml}^{-1}$ in $\mathrm{ml}^{-1}$ in lung wash* $\left(10^{\mathrm{n}}\right)$ $<1$ $3 \cdot 8$

$4 \cdot 3$

$4 \cdot 8$

$4 \cdot 7$

$4 \cdot 4$

$0 \cdot 312$ lung wash* $\left(10^{\mathrm{n}}\right)$

\section{$4 \cdot 8$}

$5 \cdot 6$

$5 \cdot 8$

$6 \cdot 1$

$6 \cdot 2$

$6 \cdot 2$

0.083

Lesion
score*
$0 \cdot 1$
$0 \cdot 3$
$0 \cdot 5$
$0 \cdot 6$
$0 \cdot 8$
$0 \cdot 8$
0.180

Lesion $0 \cdot 1$

$0 \cdot 3$

$0 \cdot 5$

$0 \cdot 6$

$0 \cdot 8$

$0 \cdot 180$

* Mean of groups of four mice.

$\dagger$ Average standard error for comparisons between means in columns, by standard analysis of variance.

Thus, the pathological changes appeared slightly more severe in mice inoculated with both $M$. pulmonis and Sendai virus than in mice inoculated with virus alone. Bacteria were not isolated from the lungs of any of the mice.

\section{Effect of varying the dose of Sendai virus on subsequent resistance to infection with M. pulmonis 6 d later}

Six days after inoculation with Sendai virus both the severity of lesions in the lungs and the degree of resistance to infection with $M$. pulmonis, as measured by the number of mycoplasma $\mathrm{ml}^{-1}$ in lung washings $24 \mathrm{~h}$ after exposure, appeared directly related to the initial dose of virus (Table 2). No bacteria were isolated from lung washings.

Effect of varying the length of time between inoculation of Sendai virus and subsequent exposure to $M$. pulmonis or $S$. aureus on resistance to infection with mycoplasma and bacteria

Maximum numbers of Sendai virus were found in lung washings $6 \mathrm{~d}$ after inoculation with virus. No virus was isolated from lung washings taken 8 or more days after inoculation. Lung lesions, as indicated by the lung wash cell count and histopathology, were most severe between days 6 and 10 after inoculation of virus. By day 13 the lung lesions were resolving (Table 3). 
Mixed respiratory infections in mice

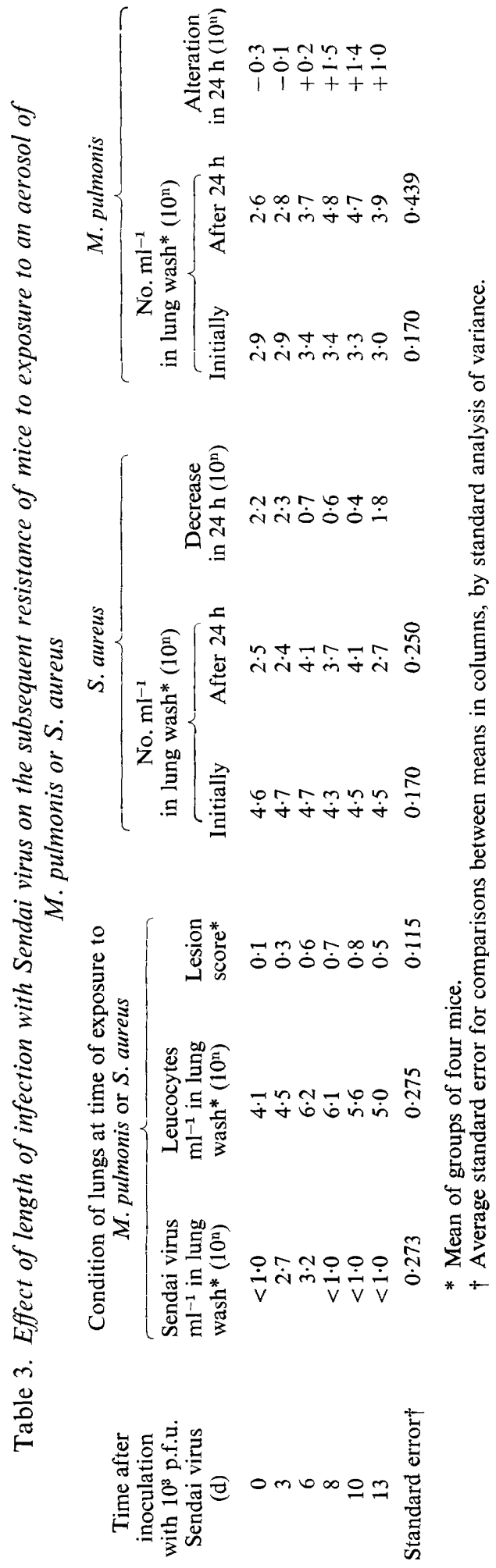



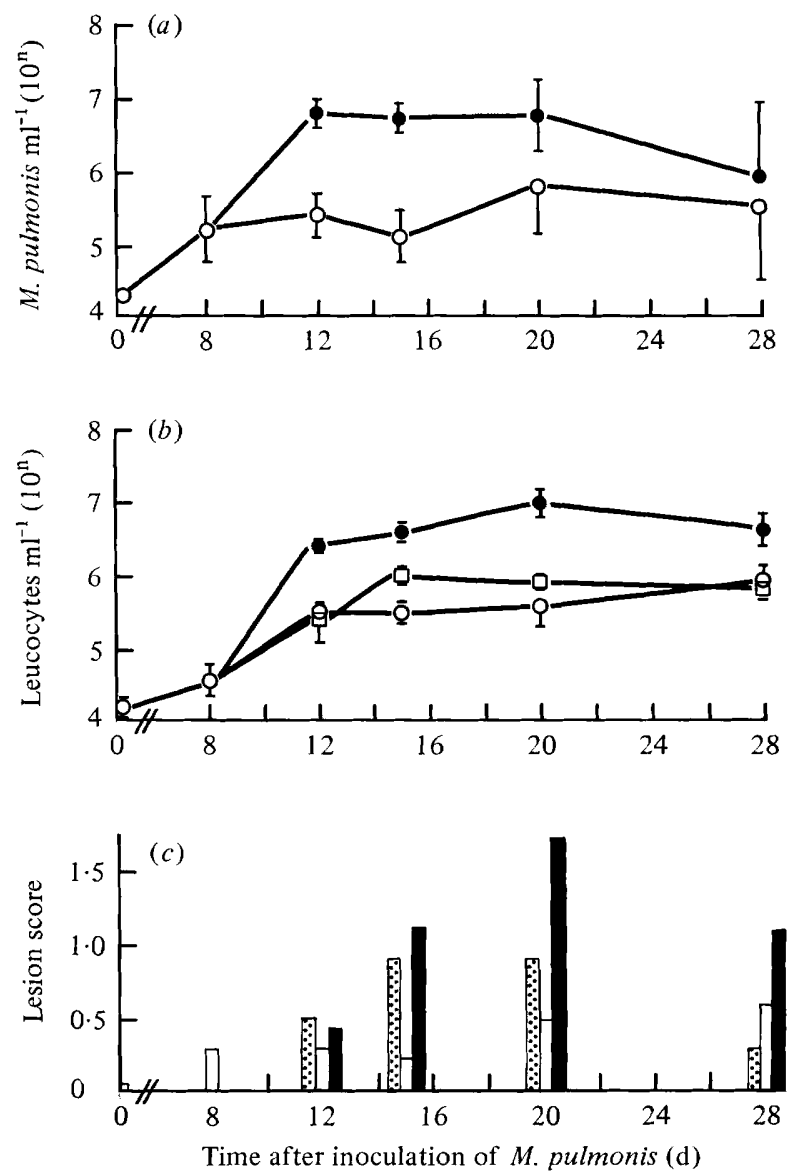

Fig. 2. Effect of Sendai virus in mice infected with $M$. pulmonis. Mice were inoculated i.n. with virus $8 \mathrm{~d}$ after i.n. inoculation of $M$. pulmonis. Each point represents the mean from groups of four mice together with the standard deviation. (a) Number of c.f.u. $M$. pulmonis $\mathrm{ml}^{-1}$ in lung washings from mice infected with mycoplasma alone $(O)$ or with mycoplasma and virus $(\bullet)$. (b) Number of leucocytes $\mathrm{ml}^{-1}$ in lung washings from mice infected with mycoplasma alone $(\bigcirc)$, virus alone $(\square)$ or mycoplasma and virus ( $\bullet$ ). (c) Lesion score in mice infected with mycoplasma alone ( $\square$ ), virus alone (国) or mycoplasma and virus ( $\square$ ).

The pattern of change in the resistance of mice to subsequent infection with either $S$. aureus or $M$. pulmonis was very similar throughout the period of observation with the reduction of resistance to $S$. aureus occurring slightly earlier (day 6) than that to M.pulmonis (day 8). By day 13, resistance to both organisms showed signs of returning to normal with that to $S$. aureus again being ahead of $M$. pulmonis (Table 3 ). Thus the change in resistance correlated with the increase in lung wash cell counts and histopathological lesions.

\section{Effect of inoculating Sendai virus into mice infected with $M$. pulmonis 8 d previously}

The numbers of mycoplasmas isolated from lung washings were significantly higher $(P<0.001$, Student's $t$ test) on days 12 and 15 in mice superinfected with Sendai virus compared with mice infected with $M$. pulmonis alone (Fig. 2a). Mycoplasmas were not isolated from lung washings of mice inoculated with Sendai virus alone and no adventitious bacteria were isolated.

Intranasal inoculation of mice with either mycoplasmas alone or Sendai virus alone 
induced an increase in the number of leucocytes present in lung washings (Fig. $2 b$ ). However, the number of cells present in lung washings of mice infected with both agents was greater than would be expected from an additive effect of the two agents alone. The lesions induced by inoculation of this dose of mycoplasma were not very severe (Fig. $2 c$ ). The lesions observed in mice infected with virus alone were most severe 7 to $12 \mathrm{~d}$ after inoculation of Sendai virus. Lesions in mice infected with both virus and mycoplasmas were very similar to those induced by virus alone when compared $7 \mathrm{~d}$ after inoculation of the virus. Twelve days after inoculation of the virus, the lesions were more severe in mice infected with both agents than in mice infected with either agent alone.

This increase in the severity of lung lesions could not be explained in terms of greater virus growth in mycoplasma-infected mice than in normal mice. In fact the reverse seems to be indicated. The numbers of p.f.u. Sendai virus present in lung washings taken from mycoplasma-infected and normal mice, respectively, on days 4 and 7 after inoculation with Sendai virus, were $10^{3 \cdot 0 \pm 1 \cdot 19}$ and $10^{4 \cdot 9 \pm 0 \cdot 20}$, and $10^{0 \cdot 8 \pm 0 \cdot 88}$ and $10^{2 \cdot 8 \pm 0 \cdot 41}$. Virus was not isolated from mice sampled after day 7. This apparent inhibitory effect of M. pulmonis infection on Sendai virus replication was also observed in two further similar experiments.

\section{DISCUSSION}

Mycoplasma pulmonis grows more rapidly in the respiratory tract of mice infected with Sendai virus than in the respiratory tract of mice not so infected. In many respects the effects of Sendai virus in decreasing host resistance to $M$. pulmonis and $S$. aureus are similar. The effect of Sendai virus is related to the dose of virus inoculated for both mycoplasmas (Table 2) and S. aureus (Jakab, 1975). Furthermore, the relation between decreased host resistance and the time after inoculation of Sendai virus is similar for mycoplasmas and bacteria (Table 3). The ability of Sendai virus to increase the severity of an existing mycoplasma infection is of particular interest since it is possible that low grade chronic mycoplasma infections may become more severe as a result of a transient virus infection. The multiplication of virus appeared to be slightly reduced in mice infected with $M$. pulmonis. A possible explanation of this is that the large number of leucocytes, mostly neutrophils, present in the bronchioles may inhibit attachment of virus to target cells either physically or by phagocytosis. Alternatively the mycoplasma infection might stimulate non-specific virus inhibitors such as interferon (Cole et al., 1976).

As seen with $S$. aureus and Sendai virus in mice (Jakab \& Green, 1972), decreased host resistance to $M$. pulmonis in mice infected with Sendai virus seems to be related to the extent of virus-induced lung pathology rather than to the titre of virus in lung washings at the time of inoculation with mycoplasmas. Thus, increased susceptibility of mice to M. pulmonis was still evident $13 \mathrm{~d}$ after inoculation of mice with virus, at which time no virus was demonstrable in lung washings. This implies that the ways in which the virus decreases resistance of the lung to bacteria, whether it is the mucosal lesion or an effect on local defence mechanisms such as the alveolar macrophage (Jakab \& Green, 1972), may be the same as those which result in increased susceptibility to mycoplasmas.

In contrast to the effect of Sendai virus infection on the resistance of mice to mycoplasmas and bacteria, $S$. aureus was killed just as rapidly in the lungs of mice infected with $M$. pulmonis as in mice not infected with mycoplasma. This lack of effect of the mycoplasma infection on the rate of disappearance of viable bacteria was surprising since lesions induced by $M$. pulmonis were more severe than those induced by Sendai virus. In addition, this strain of $M$. pulmonis results in the loss of ciliary activity in mouse tracheal organ cultures (Taylor, unpublished observations), and if this effect occurs in vivo it might be expected to affect bacterial clearance.

These observations suggest that the lung lesions per se do not appear to be responsible for decreased host resistance. This is in accord with the findings of Jakab \& Green (1973) 
who demonstrated that a lesion induced in the respiratory tract by means of tuberculin did not affect the resistance of mice to bacteria. Furthermore, pneumonia induced in guineapigs with Brucella suis increased their resistance to Bacillus anthracis (Henderson, 1964). It should be pointed out that the lesions induced by Sendai virus and M. pulmonis in CBA mice are different. Mycoplasma pulmonis induces a lesion consisting of peribronchial accumulations of lymphoid cells accompanied by infiltration of the parenchyma with neutrophils and macrophages. Sendai virus induces an infiltration of mononuclear cells in the lungs of this strain of mouse but destruction of the lung architecture, particularly the epithelium, is also evident. The pathogenesis of Sendai virus infection in mouse lung has been described (Robinson et al., 1968).

Many reports have been made of virus infections decreasing the resistance of animals to subsequent bacterial infection, e.g. influenza virus and parainfluenza virus (Harford et al., 1949; Degre \& Glasgow, 1968; Jakab \& Dick, 1973). There have also been reports of Newcastle disease virus and infectious bronchitis virus of chickens affecting susceptibility to M. gallisepticum infections (Adler et al., 1962; Dunlop et al., 1964).

Fabricant (1969) reported a higher incidence of deaths in chickens inoculated with both $M$. gallisepticum and $E$. coli compared with birds inoculated with either agent alone. Furthermore, mice inoculated with both $M$. pulmonis and $P$. pneumotropica had more extensive lesions than mice inoculated with one of the agents, but these effects might have been additive (Brennan et al., 1969). Liu et al. (1972) did not observe any increased multiplication of pneumococci in the lungs of hamsters inoculated previously with $M$. pneumoniae.

The results reported here show that whereas Sendai virus infection of mice decreases their resistance to respiratory infection with bacteria and mycoplasmas, $M$. pulmonis infection does not decrease resistance to bacteria. These findings indicate that mycoplasmas do not affect the resistance of the lung to bacteria in the same way as do viruses.

We thank Mrs J. Collins for her assistance in sampling mice and titrating mycoplasmas, Miss S. Hamilton and Mr A. P. Collins for growing and titrating the virus. We are grateful to Dr G. J. Jakab for kindly supplying Staphylococcus aureus FDA 209P. The advice and help of $\mathrm{Mr}$ A. Patterson with the statistical analyses is gratefully acknowledged.

\section{REFERENCES}

Adler, H. E., McMartin, D. A. \& Ortmayer, H. (1962). The effect of infectious bronchitis virus on chickens infected with Mycoplasma gallisepticum. Avian Diseases 6, 267-274.

Brennan, P. C., Fritz, T. E. \& FlynN, R. J. (1969). Role of Pasteurella pneumotropica and Mycoplasma pulmonis in murine pneumonia. Journal of Bacteriology 97, 337-349.

Cole, B. C., Overall, J. C., Lombardi, P. S. \& GLASGOW, L. A. (1976). Induction of interferon in ovine and human lymphocyte culture by mycoplasmas. Infection and Immunity 14, 88-94.

Degre, M. \& Glasgow, L. A. (1968). Synergistic effect of viral-bacterial infection. I. Combined infection of the respiratory tract in mice with parainfluenza virus and Haemophilus influenzae. Journal of Infectious Diseases 118, 449-462.

Dunlop, W. R., Parke, G., Strout, R. G. \& SMITH, S. C. (1964). The effect of sequence of infection on complex respiratory disease. Avian Diseases 8, 321-327.

EAton, P. (1974). A laboratory model for respiratory disease investigation and its application to varia- tions in climatic environment. Ph.D. thesis, University of Edinburgh.

FABricant, J. (1969). Avian mycoplasmas. In The Mycoplasmatales and the L-phase of Bacteria, pp. 621-641. Edited by L. Hayflick. Amsterdam: North Holland Publishing Co.

Gourlay, R. N., Mackenzie, A. \& Cooper, J. E. (1970). Studies of the microbiology and pathology of pneumonic lungs of calves. Journal of Comparative Pathology 80, 575-584.

Harford, C. G., Leidler, V. \& Hara, M. (1949). Effect of the lesion due to influenza virus on the resistance of mice to inhaled pneumococci. Journal of Experimental Medicine 89, 53-68.

Henderson, D. W. (1964). Mixed populations in vivo and in vitro. Symposia of the Society for General Microbiology 14, 241-256.

JAKAB, G. J. (1975). Suppression of pulmonary antibacterial activity following Sendai virus infection in mice: dependence on virus dose. Archives of Virology 48, 385-390.

JAKAB, G. J. \& DiCK, E. C. (1973). Synergistic effect of viral-bacterial infection: combined infection 
of the murine respiratory tract with Sendai virus and Pasteurella pneumotropica. Infection and Immunity 8, 762-768.

JAKAB, G. J. \& GREEN, G. M. (1972). The effect of Sendai virus infection on bactericidal and transport mechanisms of the murine lung. Journal of Clinical Investigation 51, 1989-1998.

JAKAB, G. J. \& GrEEN, G. M. (1973). Effect of hypersensitivity pneumonitis on the pulmonary defense mechanisms of guinea-pig lungs. Infection and Immunity 7, 39-45.

Liu, C., Jayanetra, P., Voth, D. W., MuangMANEE, L. \& CHO, C. T. (1972). Potentiating effect of Mycoplasma pneumoniae infection on the development of pneumococcal septicemia in hamsters. Journal of Infectious Diseases 125, 603-612.

Robinson, T. W. E., Cureton, R. J. R. \& Heath, R. B. (1968). The pathogenesis of Sendai virus infection in the mouse lung. Journal of Medical Microbiology 1, 89-95.

Shaw, C., Stitt, J. M. \& Cowan, S. T. (1951). Staphylococci and their classification. Journal of General Microbiology 5, 1010-1023.

TAylor, G., Howard, C. J. \& Gourlay, R. N. (1977). Protective effect of vaccines on $\mathrm{Myco}$ plasma pulmonis induced respiratory disease of mice. Infection and Immunity 16, 422-431. 